Article

\title{
Expedient Prediction of the Fuel Properties of Carbonized Woody Biomass Based on Hue Angle
}

\author{
Yuta Saito ${ }^{1}$, Kiyoshi Sakuragi ${ }^{2, *}$ (D) , Tetsuya Shoji ${ }^{2}$ and Maromu Otaka ${ }^{2}$ \\ 1 Hokuriku Electric Power Company, 15-1 Ushijimacho, Toyama 930-8686, Japan; yuta.saito@rikuden.co.jp \\ 2 Energy Engineering Research Laboratory, Central Research Institute of Electric Power Industry, 2-6-1 \\ Nagasaka, Yokosuka, Kanagawa 240-0196, Japan; s-tetsu@criepi.denken.or.jp (T.S.); \\ ootaka@criepi.denken.or.jp (M.O.) \\ * Correspondence: sakuragi@criepi.denken.or.jp; Tel.: +81-70-6638-2037; Fax: +81-46-856-3346
}

Received: 17 April 2018; Accepted: 4 May 2018; Published: 8 May 2018

\begin{abstract}
Woody biomass co-firing-based power generation can reduce $\mathrm{CO}_{2}$ emissions from pulverized coal boilers. Carbonization of woody biomass increases its calorific value and grindability, thereby improving the co-firing ratio. Carbonized biomass fuel properties depend on moisture, size and shape of feedstock, and carbonization conditions. To produce carbonized biomass with stable fuel properties, the carbonization conditions should be set according to the desired fuel properties. Therefore, we examined color changes accompanying woody biomass carbonization and proposed using them for rapid evaluation of fuel properties. Three types of woody biomasses were carbonized at a test facility with a capacity of 4 tons/day, and the fuel properties of the obtained materials were correlated with their color defined by the $L^{*} a^{*} b^{*}$ model. When fixed carbon, an important fuel property for carbonization, was $25 \mathrm{wt} \%$ or less, we observed a strong negative correlation, regardless of the tree species, between the hue angle, $h_{a b}$, and fixed carbon. The $h_{a b}$ and fixed carbon were correlated even when the fixed carbon exceeded $25 \mathrm{wt} \%$; however, this correlation was specific to the tree species. These results indicate that carbonized biomass fuel properties such as fixed carbon can be estimated rapidly and easily by measuring $h_{a b}$.
\end{abstract}

Keywords: carbonization; woody biomass; color analysis; fuel properties; fixed carbon

\section{Introduction}

Woody biomass (WB) is an abundant, renewable, and carbon-neutral energy source that is often considered to be a suitable alternative to fossil fuels [1]. Even in Japan, a number of large pulverized-coal-fired power plants have incorporated biomass co-firing to reduce $\mathrm{CO}_{2}$ emissions. However, compared to coal, WB has a remarkably poor grindability [2] and low calorific value. Therefore, to increase the biomass co-firing ratio in existing pulverized coal boilers, biomass modifications via pre-treatment are required.

Steam explosion and carbonization are well-known pre-treatment techniques that can be used to prepare WB for co-firing in pulverized coal boilers. The former technique features the use of high-temperature and high-pressure steam to disrupt and swell wood microstructures by rapid decompression [3]. Conversely, carbonization is a pyrolysis process used to decompose certain structural components of WB by heating in an inert (i.e., oxygen-free) atmosphere [4,5]. Although steam explosion processing does not significantly affect the caloric value, this parameter (as well as grindability) is greatly increased by carbonization [6]. In addition, carbonization was shown to reduce the chlorine content of biomass [7] and improve its hydrophobicity [8], thus allowing carbonized WB to be used in pulverized coal boilers at a high co-firing ratio $[9,10]$. 
The above-mentioned carbonization-induced property changes result from the thermal decomposition of cellulose, hemicellulose, and lignin, which are the main components of WB [11]. Moreover, numerous studies on WB carbonization [11-15] have shown that the properties of carbonized biomass strongly depend on its origin (tree species), moisture content, treatment time, and shape. Thus, the stable production of carbonized biomass with desired properties requires a rapid analysis of fuel properties, which have to be reflected in the operating conditions of the production process in a timely manner. To date, the design of rapid and expedient methods of measuring the properties of biomass-derived modified fuel has been extensively investigated. For example, Kubojima et al. [16] correlated the weight reduction of torrefied wood chips with their color change, whereas Strandberg et al. [17] used thermogravimetric and multivariate analyses for accurate elemental composition prediction. Moreover, Lestander et al. [18] showed that near-infrared spectroscopy can be used for caloric value, carbon, oxygen, hydrogen, ash, volatile matter, and fixed carbon content predictions, claiming that the production of heat-treated biomass could be controlled by spectral measurements. Lindström et al. [19] investigated the changes in appearance caused by carbonization and showed that the caloric value and chemical properties of carbonized WB can be assessed by using infrared spectroscopy. Tooyserkani et al. [20] correlated the lightness of steam-explosion-treated specimens with their carbon content, thus demonstrating that the properties of carbonized WB could be determined by weight measurements. However, despite the above methods, rapid and expedient measurement of the fuel properties of carbonized woody biomass with a high proportion of fixed carbon is still difficult. Herein, three types of WB were carbonized at $200-450{ }^{\circ} \mathrm{C}$, i.e., in the temperature range resulting in the largest fuel property changes [21,22], and the fuel properties of the obtained carbonized WB were correlated with its color.

\section{Materials and Methods}

\subsection{Materials and Carbonization Process}

Three types of raw WB, namely, rubber tree (Hevea brasiliensis) stems, softwood (mixture of equal amounts of spruce and pine) bark, and lumber waste were selected as low-cost potential renewable energy resource, and conditioned into 20-mm particles. Figure S1 shows the outer appearance of the test facility (capacity $=4$ tons / day) used for carbonization [23]; the carbonizer comprises of an externally heated rotary kiln. To obtain a wide range of different characteristics and qualities of carbonized biomass, the raw WB was treated under various conditions at a biomass feed rate of $144 \mathrm{~kg} / \mathrm{h}$, inner cylinder rotation speed of $5 \mathrm{rpm}$, and carbonization temperatures of $300-410^{\circ} \mathrm{C}$. At the exit-end of the kiln, carbonized WB was sampled and used for further experimentation

\subsection{Fuel Property Measurements}

Proximate analysis (ash, volatile matter, and fixed carbon), elemental analysis (carbon, hydrogen, nitrogen, oxygen, and sulphur), and measurement of the higher heating value of raw and carbonized WB were in accordance with standard methods, namely, the JIS-M8812 (Coal and Coke-Methods for Proximate Analysis), JIS-M8813 (Coal and Coke-Determination of Constituents), and JIS-M8814 (Coal and Coke Determination of Gross Calorific Value by the Bomb Calorimetric Method, and Calculation of Met Calorific Value) methods, respectively.

\subsection{Color Measurements}

The color of carbonized WB was characterized by using a color meter (TES135A Plus; TES Electrical Electronic Corp, Taipei, Taiwan), and the obtained information was represented in the $L^{*} a^{*} b^{*}$ color space, with $L^{*}$ representing lightness and $a^{*}$ and $b^{*}$ expressing chromaticity. Based on the above representation, the hue angle $\left(h_{a b}\right)$ was defined as $h_{a b}=\tan ^{-1}\left(b^{*} / a^{*}\right)$.

To measure color differences, the carbonized WB was pulverized by using a cutting mill (Wonder Blender; Osaka Chemical Co., Ltd., Osaka, Japan) and sieved to a 200-mesh size. 


\section{Results and Discussion}

\subsection{Properties of Carbonized WB}

Table 1 shows the fuel properties of raw WB (i.e., specimens for carbonization treatment) and carbonized WB. Previous studies have shown that carbonization increases the fixed carbon content and calorific value while decreasing the amount of volatile matter [24,25]. Similarly, we herein observed carbonization-induced increases of the fixed carbon content, ash content and calorific value, as well as a decrease of volatile matter and oxygen contents. The carbonization temperature depended on the type of raw material that was used even in cases of those with nearly identical fuel properties. For example, No. R-8, B-9, and W-7 in Table 1 samples were obtained by carbonization at 339, 315, and $381{ }^{\circ} \mathrm{C}$, respectively, even though all of them had a $\sim 31 \mathrm{wt} \%$ of fixed carbon. Thus, the stable production of carbonized WB with desired fuel properties using carbonization temperature as an operation parameter was challenging, as it required carbonization conditions to be set according to raw material characteristics such as the tree species, chip size, and moisture content.

Table 1. Fuel properties of raw and carbonized WB samples.

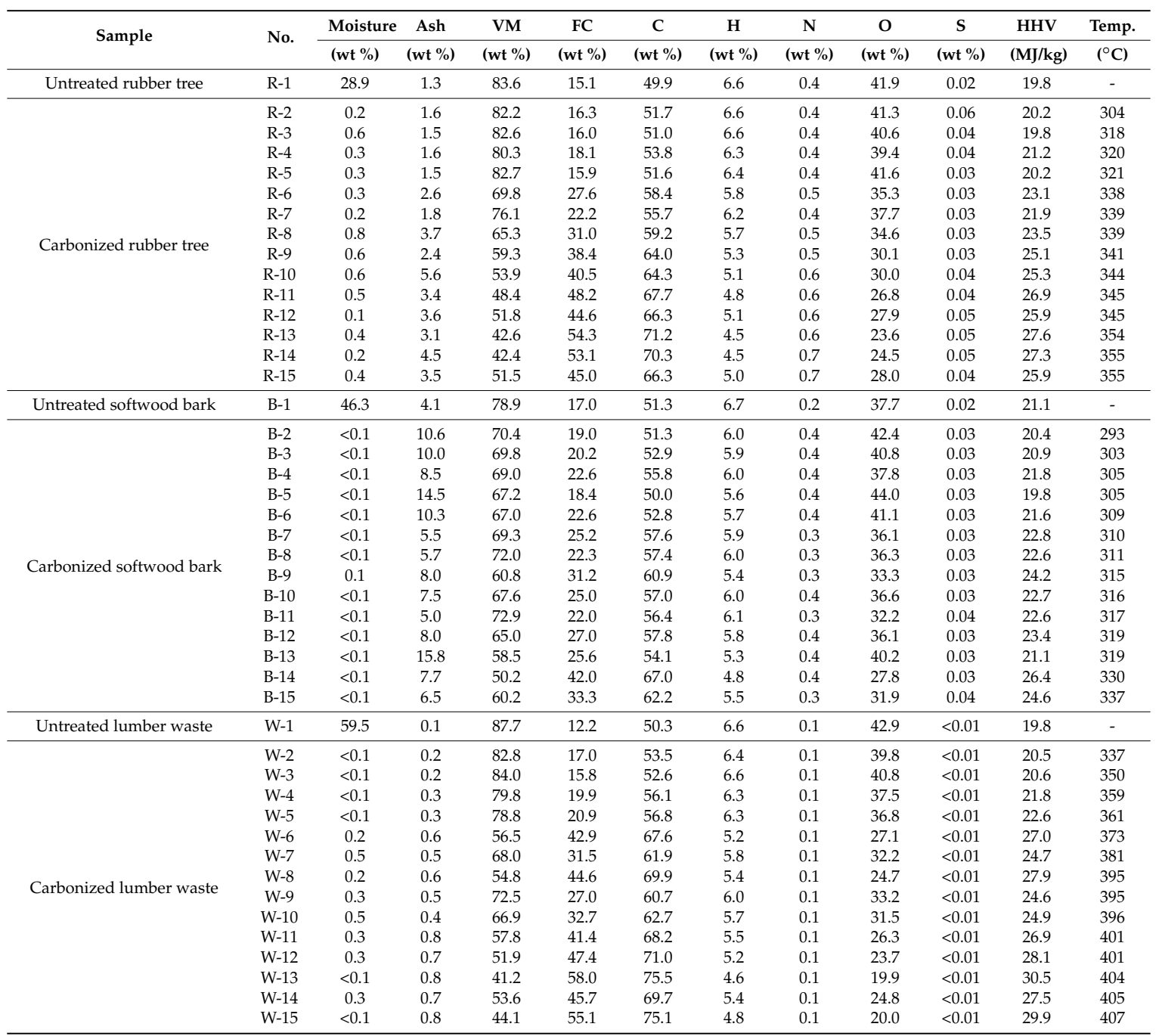

The above table lists the results for 15 samples of raw and carbonized WB (R, rubber tree; B, softwood bark; W, lumber waste) for each type of material studied in order of the increasing carbonization temperature. All analyses were performed according to standard procedures (JIS-M8812, JIS-M8813, and JIS-M8814). VM = volatile matter; $\mathrm{FC}=$ fixed carbon; $\mathrm{HHV}=$ higher heating value; Temp. = carbonization temperature. 


\subsection{Color Changes of Carbonized WB}

Figure 1 shows images of the carbonized WB samples. Specifically, these images show how the initially light brown raw WB became darker as the carbonization process progressed. At fixed carbon contents exceeding $30 \mathrm{wt} \%$, the visual discrimination of color differences became complicated, and thus, a color meter was used to obtain quantitative data (Table S1). The results listed in Table S1 show that carbonization shifted $L^{*}$ from white to black, $a^{*}$ from red to green, and $b^{*}$ from blue to yellow. In addition, the numerical values of $a^{*}$ and $b^{*}$, which show the degree of color on the red-green and yellow-blue axes, respectively, decreased with increasing fixed carbon content; these results indicate that the carbonized WB was more green/blue than raw WB.

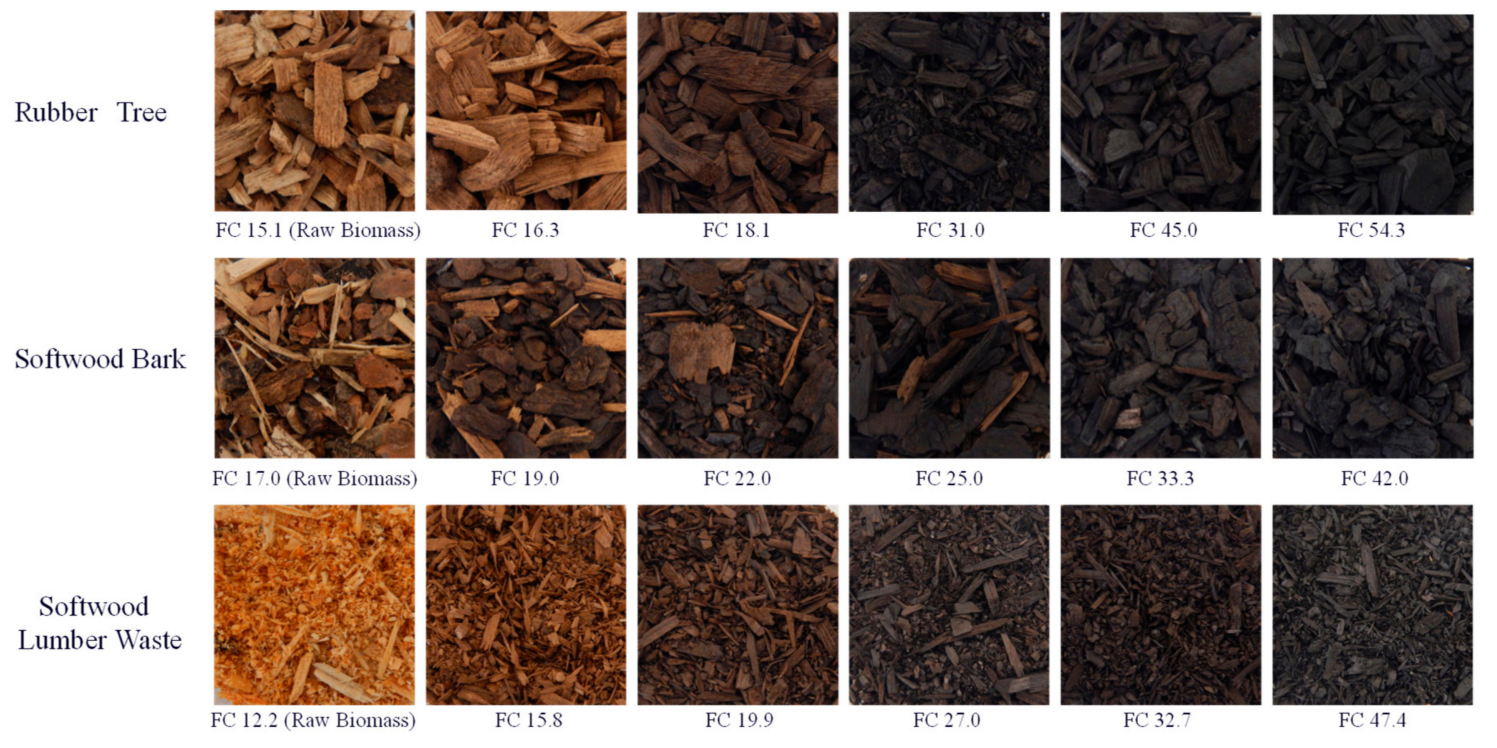

Figure 1. WB color changes observed during carbonization. FC = fixed carbon.

\subsection{Relationship between the Color and Properties of Carbonized WB}

Figure $2 \mathrm{a}, \mathrm{b}$ show that the $a^{*}$ and $b^{*}$ values of carbonized WB decreased with the increasing fixed carbon content, and the above decrease was rapid at fixed carbon contents of $25 \mathrm{wt} \%$ or less, but the decrease gradually slowed down at values above $25 \mathrm{wt} \%$; it became extremely slow when the fixed carbon content exceeded $40 \mathrm{wt} \%$, with $a^{*}$ and $b^{*}$ values converging to $\sim 3.0$ and zero, respectively. Thus, fixed carbon contents of carbonized WB exceeding $40 \mathrm{wt} \%$ were difficult to estimate based on $a^{*}$ and $b^{*}$ measurements.

Figure 2c shows that the $L^{*}$ values of carbonized WB decreased with the increasing fixed carbon content, and the decrease in $L^{*}$ was very rapid at fixed carbon contents of $20 \mathrm{wt} \%$ or less, but the decrease slowed down at higher values of fixed carbon content and became extremely slow at fixed carbon contents of $30 \mathrm{wt} \%$ or higher, with the convergence value equaling 20.0 . Thus, the obtained results were consistent with the difficulties encountered when visually observing the differences of lightness $\left(L^{*}\right)$ in carbonized WB samples with fixed carbon contents of $30 \mathrm{wt} \%$ or higher. Zhang and Cai [26] reported that during steam explosion treatment of $\mathrm{WB}$, the increasing temperature induces the decomposition of cellulose and hemicellulose into a variety of low-molecular-weight polysaccharides, which results in the appearance of dark color. The decomposition of lignin at high temperatures is known to result in the formation of chromophores, i.e., functional groups that strongly absorb visible light. Herein, we observed that carbonization changed the color of WB from light to dark, similar to the trend observed for the steam explosion treatment. Additionally, the obtained results indicate that it difficult to predict the fixed carbon content of carbonized WB based on $L^{*}$ since this parameter stays almost constant at fixed carbon contents of $30 \mathrm{wt} \%$ or higher. 

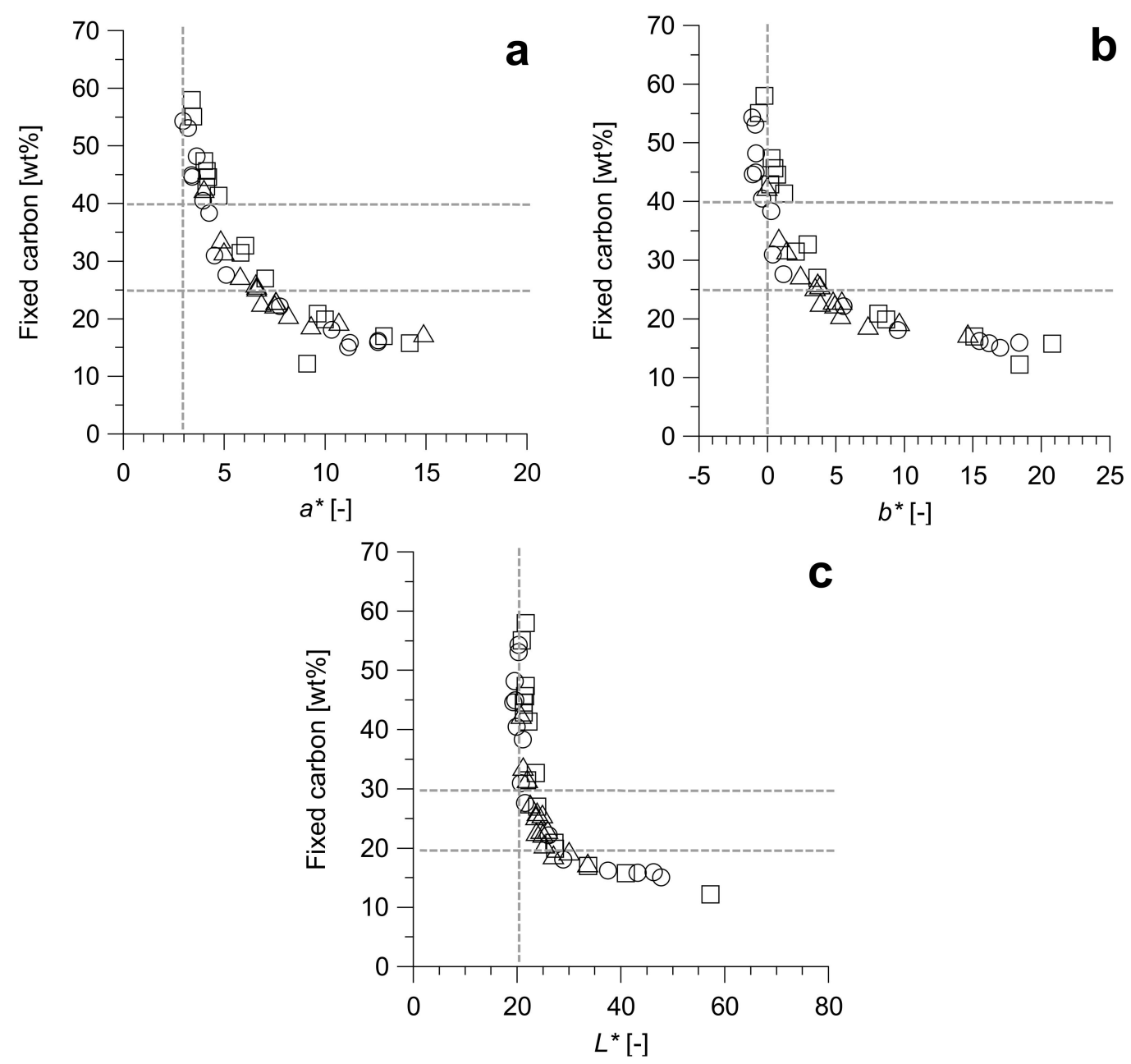

Figure 2. Correlation of the fixed carbon content of WB and (a) $a^{*} ;(\mathbf{b}) b^{*}$; and (c) $L^{*}$ values. Open circles $=$ rubber tree; open triangles $=$ softwood bark; open squares $=$ softwood lumber waste.

\subsection{Hue Angle and Fuel Properties}

Figure 3 shows that the $h_{a b}$ decreased with the increasing fixed carbon content of WB. At a fixed carbon ratio of $25 \mathrm{wt} \%$ or less, a raw material type-independent negative correlation was observed strongly, but it became material type-dependent at higher fixed carbon contents. During the production of carbonized WB with under $25 \mathrm{wt} \%$ of fixed carbon, carbonization temperatures ranged between 310 and $390^{\circ} \mathrm{C}$ and varied with the raw material type. Since this temperature range was slightly higher than that of the thermal decomposition of hemicellulose $\left(220-235^{\circ} \mathrm{C}\right)$ and matched that of the thermal decomposition of cellulose $\left(315-400^{\circ} \mathrm{C}\right)$ [27], the thermal decomposition of the above constituents probably contributed to the increase of fixed carbon content and decrease of $h_{a b}$. In comparison to the aforementioned correlations $\left(a^{*}, b^{*}\right.$, and $L^{*}$ values vs. FC), the rate of $h_{a b}$ change remained significant even when the fixed carbon content exceeded $30 \mathrm{wt} \%$. These results indicate that the fuel properties of carbonized WB (such as the fixed carbon content and caloric value) can be estimated from $h_{a b}$ if correlations between $h_{a b}$ and such properties are determined in advance for each raw material. 

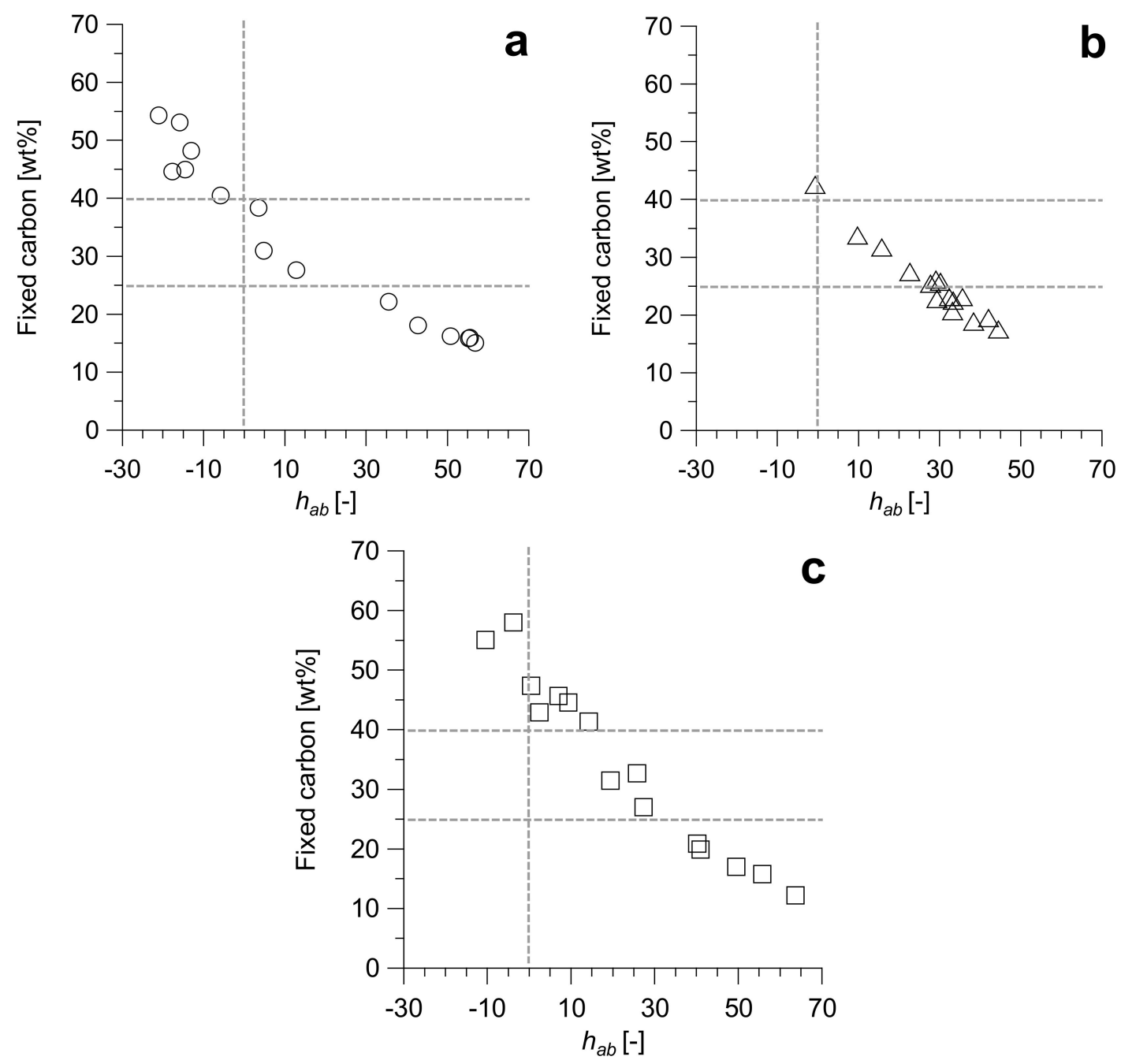

Figure 3. Relationship between the $h_{a b}$ and fixed carbon content. (a) Rubber tree; (b) softwood bark; (c) softwood lumber waste.

\section{Conclusions}

The ability to rapidly ascertain the fuel properties of carbonized WB is indispensable during its production process from raw WB. In this study, three types of woody biomasses were carbonized, and the fixed carbon of the obtained materials was correlated with their color defined by the $L^{*} a^{*} b^{*}$ model. When fixed carbon was $25 \mathrm{wt} \%$ or less, we observed a strong negative correlation, regardless of the tree species, between the hue angle, $h_{a b}$, and fixed carbon. The $h_{a b}$ and fixed carbon were correlated even when the fixed carbon exceeded $25 \mathrm{wt} \%$; however, this correlation was specific to the tree species. Therefore, $h_{a b}$ shows good potential for operation control during the carbonization processes to rapidly and easily estimate fuel properties such as the fixed carbon content of carbonized woody biomass.

Supplementary Materials: The following are available online at http:/ /www.mdpi.com/1996-1073/11/5/1191/ s1, Figure S1: Outer appearance of the carbonization test facility, Table S1: Color differences of raw and carbonized WB samples.

Author Contributions: Y.S., K.S., T.S. and M.O. designed and performed the experiments. All authors analyzed the data, discussed the results, and contributed to writing the paper. All authors have read and approved the final manuscript.

Funding: This work was supported by the Ministry of the Environment, Japan (Low Carbon Technology Research and Development Program). 
Acknowledgments: The authors are grateful to Tetsuro Matsui and Masayuki Taki at the Hokuriku Electric Power Company for their help with the operation of the carbonization facility and color measurements.

Conflicts of Interest: The authors declare no competing interests.

\section{References}

1. Lauri, P.; Havlík, P.; Kindermann, G.; Forsell, N.; Böttcher, H.; Obersteiner, M. Woody biomass energy potential in 2050. Energy Policy 2014, 66, 19-31. [CrossRef]

2. Colin, B.; Dirion, J.-L.; Arlabosse, P.; Salvador, S. Quantification of the torrefaction effects on the grindability and the hygroscopicity of wood chips. Fuel 2017, 197, 232-239. [CrossRef]

3. Biswas, A.K.; Umeki, K.; Yang, W.; Blasiak, W. Change of pyrolysis characteristics and structure of woody biomass due to steam explosion pretreatment. Fuel Process. Technol. 2011, 92, 1849-1854. [CrossRef]

4. Kambo, H.S.; Dutta, A. Strength, storage, and combustion characteristics of densified lignocellulosic biomass produced via torrefaction and hydrothermal carbonization. Appl. Energy 2014, 135, 182-191. [CrossRef]

5. Van der Stelt, M.J.C.; Gerhauser, H.; Kiel, J.H.A.; Ptasinski, K.J. Biomass upgrading by torrefaction for the production of biofuels: A review. Biomass Bioenergy 2011, 35, 3748-3762. [CrossRef]

6. Gil, M.V.; García, R.; Pevida, C.; Rubiera, F. Grindability and combustion behavior of coal and torrefied biomass blends. Bioresour. Technol. 2015, 191, 205-212. [CrossRef] [PubMed]

7. Ren, X.; Sun, R.; Chi, H.H.; Meng, X.; Li, Y.; Levendis, Y.A. Hydrogen chloride emissions from combustion of raw and torrefied biomass. Fuel 2017, 200, 37-46. [CrossRef]

8. Ciolkosz, D.; Wallace, R. A review of torrefaction for bioenergy feedstock production. Biofuels Bioprod. Biorefin. 2011, 5, 317-329. [CrossRef]

9. Koppejan, J.; Sokhansanj, S.; Melin, S.; Madrali, S. Status overview of torrefaction technologies. IEA Bioenergy Task Rep. 2015, 32, 1-54.

10. Li, J.; Brzdekiewicz, A.; Yang, W.; Blasiak, W. Co-firing based on biomass torrefaction in a pulverised coal boiler with aim of 100\% fuel switching. Appl. Energy 2012, 99, 344-354. [CrossRef]

11. Bergman, P.C.A.; Boersma, A.R.; Zwart, R.W.R.; Kiel, J.H.A. Torrefaction for Biomass Co-Firing in Existing Coal-Fired Power Stations; Energy Centre of Netherlands Report No. ECN-C-05-013; Energy Research Centre of The Netherlands (ECN): Petten, The Netherlands, 2005.

12. Correia, R.; Gonçalves, M.; Nobre, C.; Mendes, B. Impact of torrefaction and low-temperature carbonization on the properties of biomass wastes from Arundo donax L. and Phoenix canariensis. Bioresour. Technol. 2017, 223, 210-218. [CrossRef] [PubMed]

13. Sánchez, F.; San Miguel, G. Improved fuel properties of whole table olive stones via pyrolytic processing. Biomass Bioenergy 2016, 92, 1-11. [CrossRef]

14. Sadaka, S.; Liechty, H.; Pelkki, M.; Blazier, M. Pyrolysis and combustion kinetics of raw and carbonized cottonwood and switchgrass agroforest. BioResources 2015, 10, 4498-4518. [CrossRef]

15. Sadaka, S.; Sharara, M.A.; Ashworth, A.; Keyser, P.; Allen, F.; Wright, A. Characterization of biochar from switchgrass carbonisation. Energies 2014, 7, 548-567. [CrossRef]

16. Kubojima, Y.; Yanagida, T.; Yoshida, T.; Kiguchi, M. Simple estimation method for determining weight reduction in torrefied wood chips by color date. Mokuzai Gakkaishi 2017, 63, 176-182. [CrossRef]

17. Strandberg, A.; Holmgren, P.; Broström, M. Predicting fuel properties of biomass using thermogravimetry and multivariate data analysis. Fuel Process. Technol. 2017, 156, 107-112. [CrossRef]

18. Lestander, T.A.; Rudolfsson, M.; Pommer, L.; Nordin, A. NIR provides excellent predictions of properties of biocoal from torrefaction and pyrolysis of biomass. Green Chem. 2014, 16, 4906-4913. [CrossRef]

19. Lindström, S.W.; Nilsson, D.; Nordin, A.; Nordwaeger, M.; Olofsson, I.; Pommer, L.; Geladi, P. Quality assurance of torrefied biomass using RGB, visual and near infrared (hyper) spectral image data. J. Near Infrared Spectrosc. 2014, 22, 129-139. [CrossRef]

20. Tooyserkani, Z.; Sokhansanj, S.; Bi, X.; Lim, J.; Lau, A.; Saddler, J.; Kumar, L.; Lam, P.S.; Melin, S. Steam treatment of four softwood species and bark to produce torrefied wood. Appl. Energy 2013, 103, 514-521. [CrossRef]

21. Magdziarz, A.; Wilk, M.; Straka, R. Combustion process of torrefied wood biomass. J. Therm. Anal. Calorim. 2017, 127, 1339-1349. [CrossRef] 
22. Wilk, M.; Magdziarz, A.; Kalemba, I. Characterisation of renewable fuels' torrefaction process with different instrumental techniques. Energy 2015, 87, 259-269. [CrossRef]

23. Endo, Y.; Otaka, M. Development of energy self-sustained production process of Bio Upgraded Coal ${ }^{\mathrm{TM}}$ (BUC) with high co-firing rate in Pulverised Coal boilers. In Proceedings of the 9th i-CIPEC, Kyoto, Japan, 20-23 September 2016.

24. Yana, W.; Perezb, S.; Shenga, K. Upgrading fuel quality of moso bamboo via low temperature thermochemical treatments: Dry torrefaction and hydrothermal carbonisation. Fuel 2017, 196, 473-480. [CrossRef]

25. Chen, W.-H.; Cheng, W.-Y.; Lu, K.-M.; Huang, Y.-P. An evaluation on improvement of pulverised biomass property for solid fuel through torrefaction. Appl. Energy 2011, 88, 3636-3644. [CrossRef]

26. Zhang, Y.; Cai, L. Effects of steam explosion on wood appearance and structure of sub-alpine fir. Wood Sci. Technol. 2006, 40, 427-436. [CrossRef]

27. Dhyania, V.; Bhaskar, T. A comprehensive review on the pyrolysis of lignocellulosic biomass. Renew. Energy 2017, in press. [CrossRef]

(C) 2018 by the authors. Licensee MDPI, Basel, Switzerland. This article is an open access article distributed under the terms and conditions of the Creative Commons Attribution (CC BY) license (http:/ / creativecommons.org/licenses/by/4.0/). 